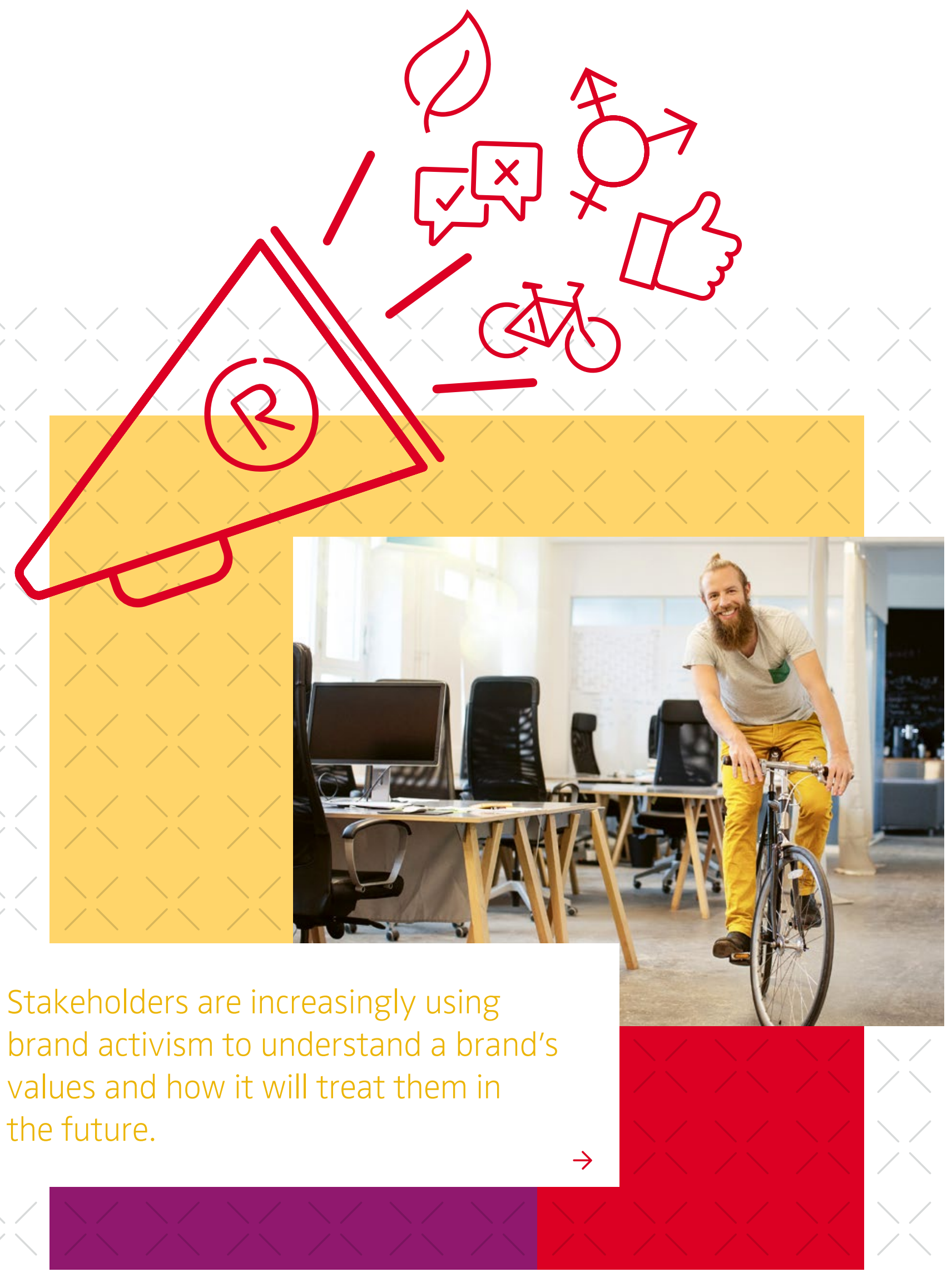




\title{
Brand Activism Is Here to Stay: Here's Why
}

\author{
Daniel Korschun
}

KEYWORDS

\section{Brand Activism, Corporate Socio-Political Activism, Advocacy}

THE AUTHOR

\section{Daniel Korschun}

Associate Professor and Marketing Department Head, Drexel University; Philadelphia, PA, USA dek46@drexel.edu
Brands increasingly embrace controversy $`$ Brand activism is perhaps the most dramatic and surprising business trend of the past decade. In years past, brand managers almost always avoided political controversy. Today, many are steering their brands directly into the partisan winds, in the hopes of reaching the figurative eye of the storm, where financial performance and societal objectives align. Each day, it seems more brands are choosing to take public stances on divisive socio-political issues. Often, the positions have no obvious tie to the brand's operations. From Black Lives Matter to LGBTQ to gun laws to COVID-19-related policy to local taxi laws, no issue appears too contentious.

Its novelty suggests to some that this may be a fad. However, one should not mistake a trend for trendiness. The reality is that brand activism is the result of powerful and long-term forces that will continue into the foreseeable future. Brand activism is here to stay, and brand managers need to understand whether and how to engage.

What makes brand activism different $\ltimes$ Having examined hundreds of such positions on socio-political issues over the past six years in my own research, I find that brand activism can be boiled down to two essential characteristics (Figure 1). First, it involves a publicly stated position. This distinguishes activism from lobbying or other forms of behind-the-scenes political influence. Brand activism is an inherently public act which plays out in advertising, social media, public relations, and other visible means.

Second, and perhaps more importantly, brand activism involves advocacy. It goes beyond simply "doing one's part" such as fulfilling a social responsibility. Rather, it seeks to proactively change public opinion and the way citizens interact with political leaders. This distinguishes brand activism from more traditional corporate responsibility or public relations efforts. A responsible company may express pride in its 


\section{FIGURE 1 > How brand activism differs from other ways of addressing socio-political issues}

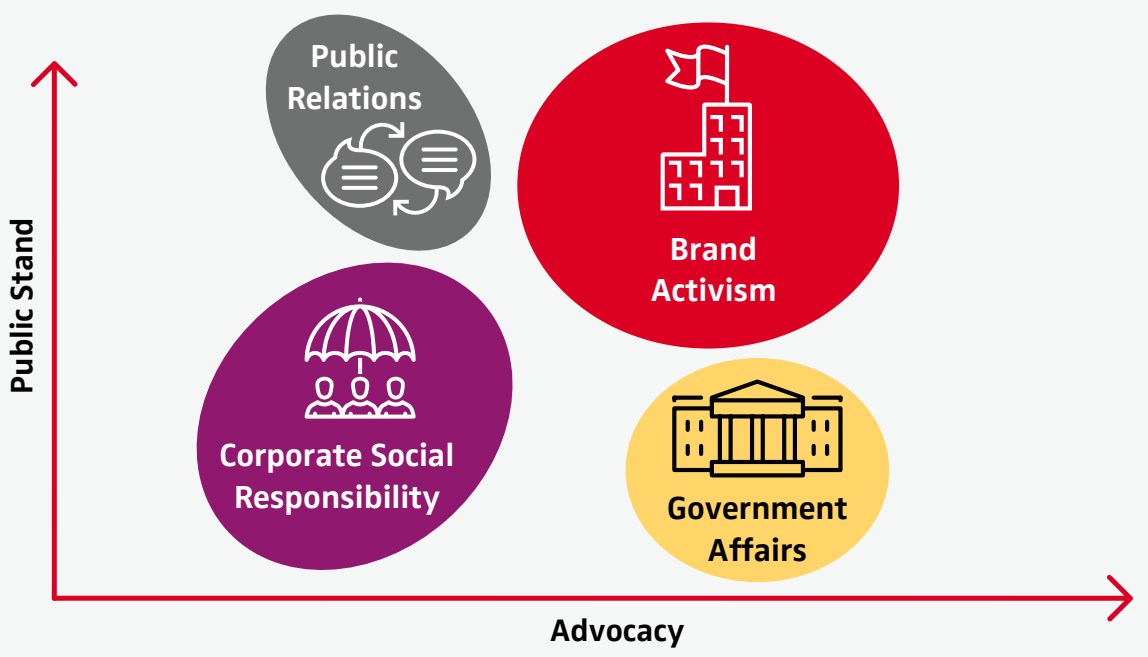

own performance on LGBTQ issues, but the activist company takes the additional step of trying to grow awareness and galvanize additional support around the issue. Activist brands seek to persuade individuals and other organizations to join their side. For those looking for an activist exemplar, consider Patagonia (Box 1).
Although brand activism may seem to have emerged spontaneously, companies have openly flirted with divisive socio-political issues before. In the 1980's and 1990's, Benetton launched a now-classic campaign confronting issues such as the mafia in Italy and race relations. Over the years, other brands have courted controversial issues now

BOX 1

Patagonia's fight against climate change

Patagonia describes itself as an activist company. It was especially active, politically speaking, during the Trump administration, when it took a hard stance against a series of policies. When then-President Trump rolled back protections for some Federal parklands, Patagonia famously declared on its website and social media "The President stole your land." By opposing laws that relax environmental protections and supporting those that tackle climate change, the brand is putting time, money, and indeed its reputation at stake in a bid to deliver on its stated purpose. Patagonia launched Action Works, which tries to connect customers with environmental action groups that it supports, magnifying its voice through those customers. It has also run ads asking people not to buy its products to encourage more sustainable lifestyles. More recently, Patagonia has widened its scope of its activism, beyond environmental issues. In 2021, it donated \$1 million to fight restrictive voting laws in Georgia.

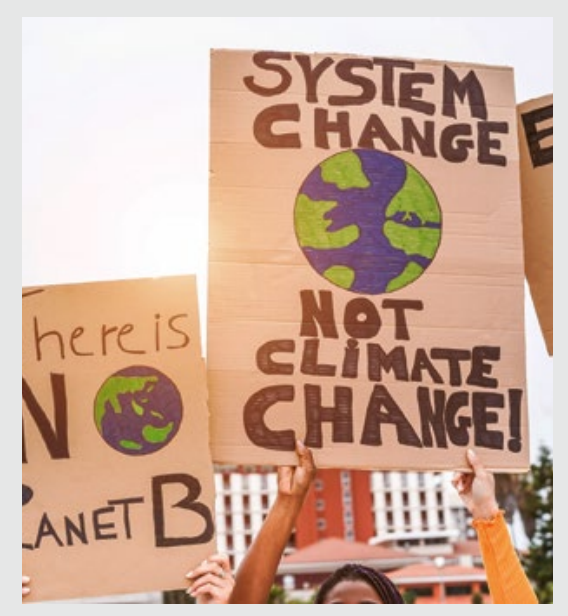


BOX 2

\section{UEFA and the Pride flag}

In June 2021, the Mayor of Munich requested that the city's stadium be lit in rainbow colors during the Euro 2020 match between Germany and Hungary; the city government wanted to take a stand against homophobia a few days after anti-LGBTQ laws just passed in Hungary. UEFA, which governed the game, declined the request, explaining that it came to its decision because it is a politically "neutral organization." This is when some global and many local brands jumped into the fray. Major sponsors such as VW and Heineken changed their banner advertising on the pitch to incorporate rainbow imagery. Other stadiums in Germany and other countries did light their stadiums in rainbow colors on the day of the match rainbow flags popped up in ads everywhere.

This incident demonstrates some of the key questions brands need to ask themselves when they consider activistic action: Should they enter a public controversy and support a disputed cause? Which issues are worth standing up for - also from a business perspective? How about spontaneous activism - was not what happened just "rainbow-washing" without true engagement and might backfire? And as for FiFa - is not prohibiting a statement a statement by itself?

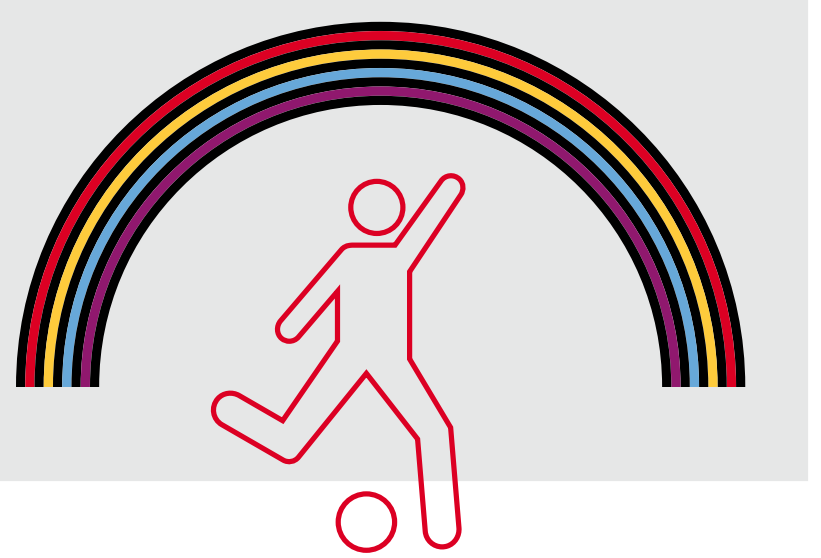

and then, but only in recent years has the phenomenon truly reached the mainstream. This did not happen by chance. Rather, it is the culmination of forces that have been building for decades.

The forces behind the trend $`$ We live in a politically charged time. The Pew Center finds that "the level of division and animosity [in the United States] - including negative sentiments among partisans toward the members of the opposing party - has only deepened." The evidence suggests that such polarization is increasing and spreading globally. A Carnegie Endowment study finds that divisive leaders, corruption, and even economic growth are each driving polarization in countries around the world. The result is a world in which there are many more people at the far left and far right of the political spectrum and a smaller and less vocal group in the middle. Europe seemed less divided, but just recently the continent experienced a broad public debate on LGBTG rights around the European Football/Soccer championship, with lots of brands joining in (see Box 2).

The political landscape explains why politics might come up more frequently for brands; but it is insufficient in explaining why brands might want to throw their hat into the ring. The primary reason brand activism has exploded is the accretion of consumer expectations. Consumers used to differentiate companies based on price and quality. However, in a market in which differences along those dimensions are difficult to discern, consumers look deeper. Almost inevitably, consumers begin to ask not what is being sold but who is selling it.

Many brands have risen to this challenge and put more focus on their values. It is by now commonplace for brands to tout their commitment to social and environmental responsibility. But consider a scenario in which a brand that has made frequent statements about its commitment to diversity is asked about its view on, say a new piece of legislation on LGBTQ rights. Based on its prior rhetoric, consumers would have good reason to expect that the brand would have an opinion on the law. If it evades giving an opinion, consumers will naturally wonder why. Put simply, brands need to deliver on their stated values. They are the benchmark against which consumers set expectations.

What many marketers overlook $\times$ What many brand managers do when deciding whether to tackle a socio-political issue is to gauge how many customers will be delighted vs. how many will be enraged by the brand's position. The 
FIGURE 2 > Key forces driving brand activism

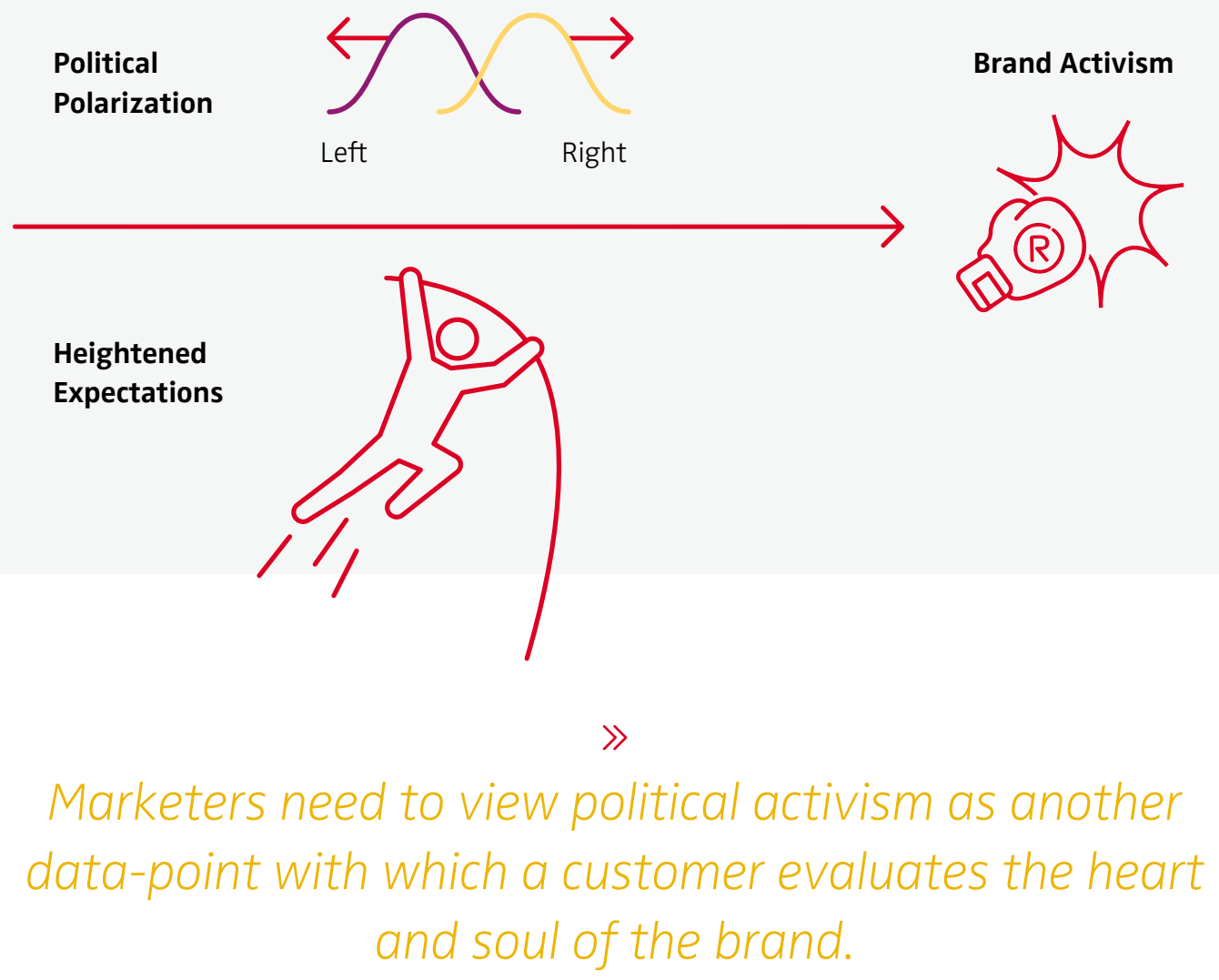

«

traditional wisdom is that customers who disagree with an activist stance will feel alienated, while customers who agree will become more loyal.

While this traditional approach has merit, simply estimating what percentage of consumers agree with a stand is somewhat myopic. To explain how, I often ask marketing managers if they have any friends or family members who hold sharply different political views than their own. They almost always do. "So," I then ask, "how can you tolerate someone who disagrees with your political beliefs?" Usually the answer I get is that their friend or family member always has their back in difficult times, does not try to push their political views too aggressively, and that their friend's intentions are generally honorable.

I find the same logic at play when it comes to brands becoming politically active. People are surprisingly tolerant, as long as they feel that the brand otherwise has their interest in mind, that the brand is not too pushy about the activism, and that its intentions appear to be honorable.

Yet, too many marketers still get so caught up in how the public's beliefs align with the statement that they completely forget about the context in which that statement is interpreted. Looking at a political stand in isolation ignores the totality of the relationship, and it is the relationship that people care about.

This myopic view is partly why marketers worry so much about the risk of taking action that they grossly underestimate the risk of inaction. Avoiding taking a stand - or attempting to appear neutral on a divisive issue - can backfire, if it signals that the brand is withholding its true intentions or beliefs. Customers are left to wonder whether the brand will be adequately forthcoming in other areas, if there is a need for a product recall or a billing issue. Thus, marketers need to view political activism as another data-point with 
FIGURE 3 > How to implement brand activism to make dual success more likely

> Understand stakeholder needs

$>$ Take leadership on an issue

$>$ Walk your talk

$>$ Be transparent

> Analyze the risks of engaging in specific activism

> Monitor associations with partners and spokespeople

> Prepare for unexpected twists and turns

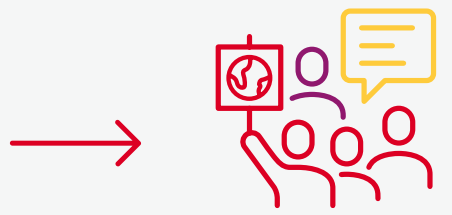

Sociopolitical impact

Business performance impact which a customer evaluates the heart and soul of the brand. Brand activism is such a potent formula because it almost always spills over to other aspects of the relationship.

How to navigate the political storm $\times$ Most marketers who are considering taking a more activist approach have twin goals. On the one hand, they want to have a political impact. On the other hand, they want to protect, and possibly even improve, their business performance. Brands do not have to give up profits or market share to be politically active, as long as they do it right. Fortunately, there are plenty of companies that have achieved this. Nike launched its campaign featuring Colin Kaepernick, the American football quarterback who knelt during the national anthem, brought considerable attention to the issue of racial injustice, and overall, the brand saw sales rise in the months during which the campaign ran. There was certainly pushback from some quarters; a few people reportedly set their Nike apparel on fire and posted the videos to social media. But most of the resistance was at the margins and was more than made-up for by the goodwill of Nike's core customers.

More recently, in the summer of 2021, some Republicans called for boycotts of Coca-Cola, UPS, and other brands that opposed a law in Georgia restricting voting access. Once again, the long-term damage to those brands has been negligible, despite the fact that millions of customers supported the law.
What can other brands take away from this and other success stories? I find a few overarching practices that can increase the likelihood of success on those twin goals of political impact and business performance (Figure 3 ).

> Understand stakeholder needs « Brands rely on a wide range of stakeholders to perform. When engaging in political activism, brands need to listen to all of these groups to understand not only how they feel about the stand, but also how it might affect their relationship with the company. Consumers may be concerned with product quality and may look at a political stand - or avoidance of one - to understand how the company might react in the case of a product failure or recall. As Buder and Kittinger-Rosanelli suggest in their article (p. 50), prospective employees want a place where they can express themselves fully and brand activism can signal that. Besides, shareholders can also find value in brand activism if they see it as a means to grow the brand's profitability, according to research by Warren (p. 32). Overall, marketers need to assess the stand in light of how it affects these relationship drivers.

> Take leadership on an issue $\times$ People generally do not like to work with brands that are risky. However, brand activism is a bit different in this regard. Counterintuitively, people admire brands that take political stands that are risky. This is because, when a brand takes a risky political stand, it can signal that the brand genuinely cares about 


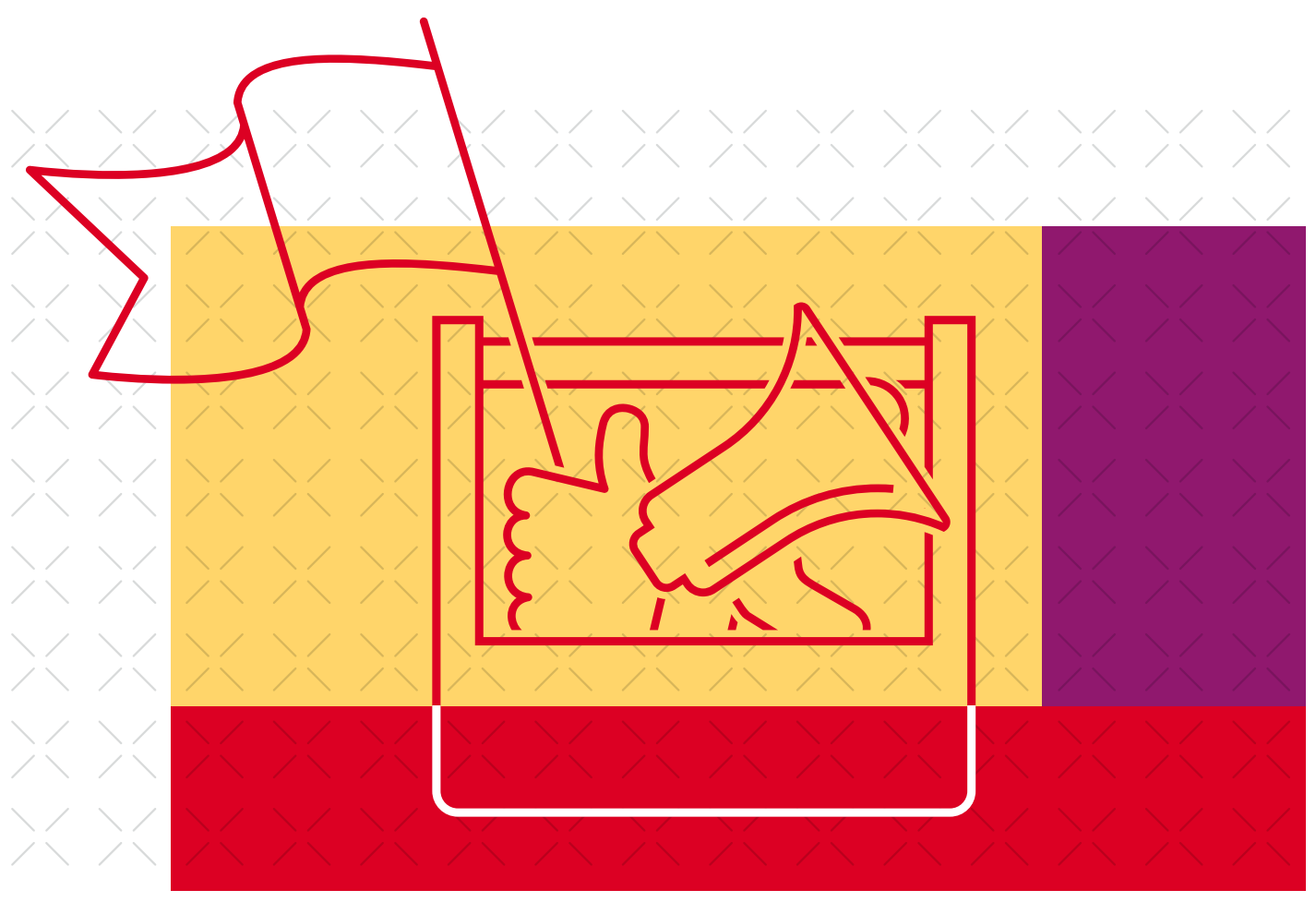

the issue, otherwise it would not risk business performance in order to take the stand. In other words, brand activism can be seen as courageous, as long as the brand has something to lose. This is why brands that take a leadership position tend to be rewarded more than brands that wait for peer brands to make the first move. A brand can display leadership on an issue by being the first to address it or by taking a forceful enough position on it that it sets the tone for discourse on the topic.

$>$ Walk your talk ׳ Showing commitment is sometimes harder than anticipated. It is not enough to publicly stand up for a cause. Brands that take a stand may invite increased scrutiny of their internal procedures as well. Brands that support diversity and racial equality, but do not reflect these values in their own workforce, will naturally encounter problems. In our interview with Caroline
Wiertz (p. 56), we learn about the rebranding of the Bayes (formerly Cass) Business School in London in the wake of the Black Lives Matter movement. Beside changing their name, they also started initiatives for staff and students to underline that they truly care for racial equality and inclusion. Credibility is a precondition for successful activism, and it needs to be earned by acting within corporate boundaries as well.

$>$ Be transparent $\ltimes$ Showing authentic concern is important and stakeholders expect more than just a glimpse into a company's display windows to be convinced. Companies that are not transparent enough are often suspected of hiding something and might encounter reputational headwinds. These problems are typical for companies that use lobbying as their way of exercising political influence. Martin and colleagues (p. 38) find lobbying strategies

$\gg$

Showing authentic concern is important and stakeholders expect more than just a glimpse into a company's display windows to be convinced. 


\section{$\gg$ Brand activism will remain part of the marketer's playbook for as long as people use it to decide with whom they will entertain a business relationship.}

$\ll$

highly effective in terms of greater market value and other benefits. However, they also warn lobbying companies and governments alike to take the reputation problem of political marketing seriously and install rules to avoid the abuse of power of all parties involved. More transparency could be one.

> Analyze the risks of engaging in specific activism 火 Alignment of the values of key-stakeholders and socio-political initiatives reduces the risks of activism, but there are more risk-related factors. Hydock and colleagues (p. 26) show that market share plays a role: Engaging in activism may be riskier for brands with high market shares than brands with smaller shares, because dominant brands have more customers to lose and fewer to gain. One way to assess the business impact or brand impact is in terms of its effect on customer acquisition versus retention.

> Monitor associations with partners and spokespeople 火 Brand perceptions evolve based on every interaction that people have with the brand. Hill and colleagues ( $p$. 46) show how a personal brand can have disastrous effects on the business with which it is associated. They analyzed the effect of Donald Trump's actions as President of the United States on the commercial Trump brand and illustrate the destruction of its brand value over the past years. Although an extreme case, marketers can learn from it by keeping tabs on any and all personalities that are associated with the brand. These include the likely suspects such as spokespeople and paid influencers. Nevertheless, marketers should also remain attentive to the CEO, employees, partner organizations, and anyone else who may be viewed as speaking on behalf of the brand.

> Prepare for unexpected twists and turns $\times$ Fournier and colleagues (p. 18) discuss another risk that is relevant even for brands that have not chosen to be activist: Being unintentionally drawn into political controversy.
Well-known examples with extensive and harmful media coverage abound: From the coolest monkey in the jungle on an H\&M hoodie to the white-washing soap of Dove (see page 20). Risk sources and types should be identified, catalogued, and tracked to develop early warning indicators of potential trouble and to develop action plans for sudden trouble. Most importantly, marketers need foster strong ties with colleagues in government affairs, public relations, and other functions so they are ready for when surprises inevitably occur.

Our new reality $\rtimes$ Brand activism is here to stay. The bottom line is that consumers, employees, investors, and other stakeholders are increasingly using brand activism as a means to understand the brand's true values as a means to predict how it may treat them in the future. Under the right conditions, activist brands can shape the political discourse and perhaps even improve their business performance along the way. Although I have highlighted a number of key factors for brands to consider, there is no one-size-fits-all strategy, and activism may not be the right approach for all brands. What is clear, however, is that brand activism will remain part of the marketer's playbook for as long as people use it to decide with whom they will entertain a business relationship. 